\title{
Cellular cannibalism and consequent thrombocytopenia in a patient with bone marrow metastasis of malignant pleural mesothelioma: A case report
}

\author{
MEGUMI NISHIKUBO $^{1,2}$, YASUO KIN ${ }^{1}$, SHINYA TANE $^{1,2}$, KOJI NAKAMURA $^{3}$, YOSHIMI MIYAGI ${ }^{4}$, \\ AKIKO MIURA $^{5}$, WATARU NISHIO ${ }^{2}$, HIDETO SENZAKI ${ }^{4}$ and KAZUYA UCHINO ${ }^{1}$ \\ ${ }^{1}$ Department of General Thoracic Surgery, Osaka Saiseikai Nakatsu Hospital, Shibata, Kita-ku, Osaka 530-0012; \\ ${ }^{2}$ Division of Chest Surgery, Hyogo Cancer Center, Kitaouji-cho, Akashi 673-8558; \\ ${ }^{3}$ Department of Clinical Laboratory Medicine, ${ }^{4}$ Division of Pathology and ${ }^{5}$ Department of Hematology, \\ Osaka Saiseikai Nakatsu Hospital, Shibata, Kita-ku, Osaka 530-0012, Japan
}

Received December 20, 2020; Accepted May 7, 2021

DOI: $10.3892 / \mathrm{mco} .2021 .2325$

\begin{abstract}
Cellular cannibalism is a tumor activity where a cell is engulfed by another cell. This process promotes tumor cell survival under unfavorable conditions. The current report describes an extremely rare case of thrombocytopenia resulting from cellular cannibalism in a patient with bone marrow metastasis due to malignant pleural mesothelioma (MPM). A 77-year-old male presented with hemothorax and thrombocytopenia. He was diagnosed with MPM of the sarcomatoid cell type. However, his disease progressed rapidly and he died 11 days after admission. Bone marrow aspiration revealed metastatic MPM cells that had engulfed other blood cells. Accordingly, the observed thrombocytopenia was attributed to cellular cannibalism by metastatic MPM tumor cells. To the best of our knowledge, this is the first reported case of thrombocytopenia due to cellular cannibalism in a patient with this type of malignancy (MPM). The results suggested that although MPM rarely metastasizes to the bone marrow, bone marrow aspiration could be useful in such cases.
\end{abstract}

\section{Introduction}

Malignant pleural mesothelioma (MPM) is a locally aggressive tumor with poor prognosis. It is mostly related to

Correspondence to: Dr Kazuya Uchino, Department of General Thoracic Surgery, Osaka Saiseikai Nakatsu Hospital, 2-10-39 Shibata, Kita-ku, Osaka 530-0012, Japan

E-mail: mumps16@angel.zaq.jp

Abbreviations: CT, computed tomography; DIC, disseminated intravascular coagulation; MPM, malignant pleural mesothelioma; VATS, video-assisted thoracic surgery

Key words: apoptosis, blood cells, cell survival, disseminated intravascular coagulation, drug resistance, cellular cannibalism, mesothelioma, bone marrow, metastasis, thrombocytopenia asbestos exposure (1). Most malignant mesothelioma can be categorized into three histological subtypes: Epithelioid, sarcomatoid, or biphasic (mixed). Sarcomatoid and biphasic subtypes have significantly poorer prognosis and are less responsive to treatment overall (2). To diagnose MPM, the gold standard procedure is video-assisted thoracic surgery (VATS) biopsy (3).

Metastasis of a non-hematologic malignancy to the bone marrow can induce various hematologic abnormalities, which may be associated with poor prognosis. Metastasis to the bone marrow most commonly arises from prostate, breast, and lung cancers and neuroblastoma (4). In contrast, bone marrow metastasis due to MPM is very rare (5).

Cellular cannibalism is defined as the ability of a tumor cell to engulf another cell. Several studies have indicated that this process promotes tumor cell survival under unfavorable conditions (6). Although this type of cell-cell interaction has been demonstrated in various carcinomas, no report has described this phenomenon in a patient with MPM before. Herein, we describe our experience with an extremely rare case of MPM with bone marrow metastasis in which thrombocytopenia was caused by cellular cannibalism.

\section{Case report}

A 77-year-old male smoker was referred to our hospital due to hemothorax. He had a history of dyspnea and cough 20 days before this referral, and exacerbating right chest pain for several days. He had worked previously as a machine tool manufacturer and had a history of occupational asbestos exposure. A blood test results revealed anemia and thrombocytopenia (hemoglobin level: $6.6 \mathrm{~g} / \mathrm{dl}$, white blood cell count: $19.2 \times 10^{3} / \mathrm{mm}^{3}$, and platelet count: $\left.1.9 \times 10^{4} / \mathrm{mm}^{3}\right)$. A chest X-ray revealed right-sided pleural effusion. Subsequently, a chest tube was placed, and approximately $2,000 \mathrm{ml}$ of light, bloody pleural effusion was drained. A computed tomography (CT) scan performed after tube thoracotomy revealed irregular thickening of the right pleura (Fig. 1). We performed VATS pleural biopsy, and its analysis suggested MPM, sarcomatoid 
cell type. Histopathologically, this biopsy specimen contained spindle tumor cells (Fig. 2), which were positive for calretinin, D2-40, WT-1, and AE1/AE3 but negative for S-100, CD34, $\alpha$-smooth muscle actin, and desmin using an immunohistochemical analysis.

Although the amount of drainage fluid decreased over time and had become serous in appearance, the patient's platelet count did not increase $\left(1.0-3.0 \times 10^{4} / \mathrm{mm}^{3}\right)$ despite daily transfusions of 10-20 units of platelet concentrate. In contrast, this patient did not have an abnormal prolonged prothrombin time or activated partial thromboplastin time through the whole course of this disease. Therefore, a bone marrow aspiration was performed to examine the cause of thrombocytopenia. Aspirate smears revealed large, cohesive, and clustered atypical cells present at a frequency of $2.2 \%$ (Fig. 3A). These atypical cells were negative for esterase and peroxidase. In addition, some of these atypical cells had engulfed other blood cells, indicating cellular cannibalism (Fig. 3B). Immunohistochemical staining of this aspiration smear revealed positivity for AE1/AE3 (Fig. 4). Consequently, we established a final diagnosis of bone marrow metastasis of MPM (stage IV) with thrombocytopenia due to cellular cannibalism. The patient's disease progressed rapidly, and severe back pain occurred. His consciousness was impaired and he died 11 days after admission.

\section{Discussion}

We experienced a rare case of MPM with bone marrow metastasis in which thrombocytopenia occurred as a consequence of cellular cannibalism. The interesting and novel findings of this case include (i) the ability of MPM to metastasize to the bone marrow and (ii) the ability of metastatic MPM cells to cause thrombocytopenia due to cellular cannibalism.

MPM is generally considered a locally invasive tumor, and bone marrow metastasis from MPM is considered an extremely rare consequence (5). One study of postmortem records of 318 patients with MPM revealed that tumors were detected in extrathoracic organs in $55.4 \%$ of the cases, and almost all organs were involved including the liver $(31.9 \%)$, spleen $(10.8 \%)$, thyroid $(6.9 \%)$, and brain $(3.0 \%)$. Among those cases, $13.8 \%$ of patients had bone metastasis, whereas no bone marrow metastasis was detected (7). In our case, a bone marrow aspiration sample revealed large, cohesive, and clustered atypical cells that were negative for esterase and peroxidase. In other words, these atypical cells differed from bone marrow-derived cells. Immunohistochemically, these atypical cells were positive for AE1/AE3, which strongly suggested a bone marrow metastasis due to MPM, rather than scavenging macrophage.

Although we were unable to confirm presence of other MPM-specific markers such as calretinin, D2-40, or WT-1 due to insufficient specimen volume, we definitively detected epithelial marker expression. Consequently, a malignant tumor with an epithelial component was present in the bone marrow of this patient.

Of note, cellular cannibalism describes an ability of one cell to engulf another living cell (8). This phenomenon is associated with poor prognosis, and no effective treatment has been identified yet (6). In vivo, this phenomenon has been recognized in a wide range of carcinomas, including breast,

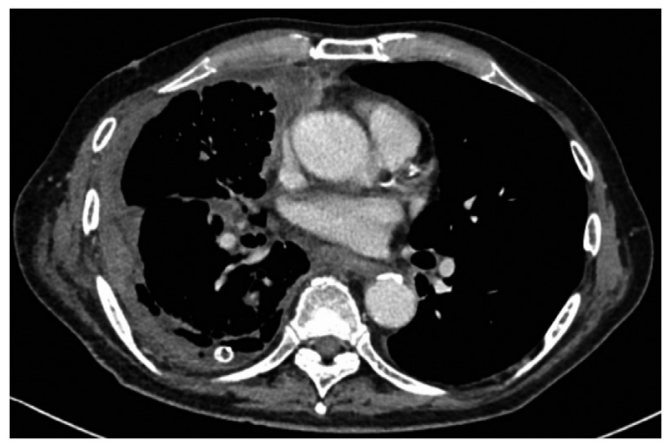

Figure 1. Computed tomography scan demonstrating irregular thickening of the right pleura.

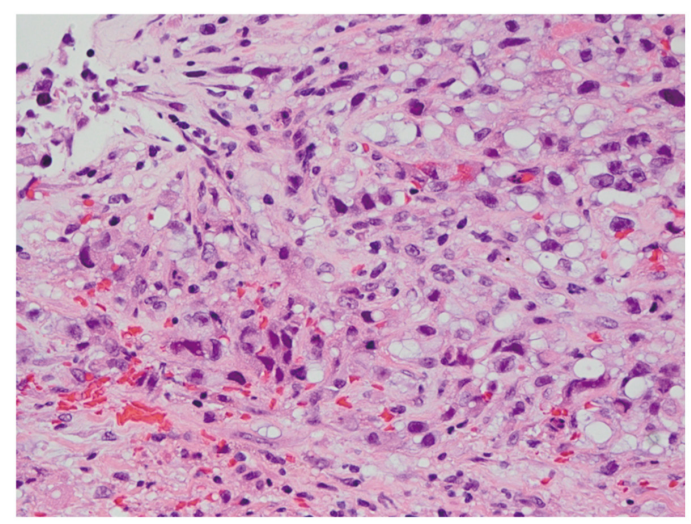

Figure 2. Analysis of pleural biopsy revealed spindle tumor cells (parietal pleura; hematoxylin and eosin stain; magnification, $\mathrm{x} 400$ ).

cervix, colon, stomach, liver, melanoma, head-and-neck, and lung malignancies (9). To date, several studies have explored potential triggers for cellular cannibalism. One in vitro experiment clarified increased presence of cannibal cells in metastatic sites relative to primary lesions. Moreover, these cannibal cells were able to survive under unfavorable conditions, such as serum starvation or acidity (6). These findings suggest that cellular cannibalism may provide nutrients and thus enable cancer cells to proliferate in metastatic organs that are intrinsically unfriendly to cell survival. Molecular genetic mechanisms for cellular cannibalistic activity are increasingly being revealed. Cellular cannibalism could be associated with microenvironment that provokes drug-resistance. Several studies of this phenomenon have indicated the potential use of new target anti-tumor strategies (10-12).

In our case, we observed that atypical cells engulfed other blood cells in the bone marrow. Nuclei collapse of the apparent normal blood cells was observed indicating cellular cannibalism. Unfortunately, we could not perform immunohistochemical staining for apoptosis markers. However, morphological features of tumor cells engulfing blood cells and their nuclei collapse highly suggested this phenomenon of cellular cannibalism. Because we detected no evidence of disseminated intravascular coagulation (DIC) or other thrombocytopenic disorders, we assumed that thrombocytopenia in this case was due to cellular cannibalism caused by metastatic mesothelioma cells in the bone marrow. Although few cases of thrombocytopenia due to cellular 
Table I. Clinical features of thrombocytopenia-inducing cellular cannibalism due to bone marrow metastasis.

\begin{tabular}{|c|c|c|c|c|c|c|}
\hline Author (year) & Type of cancer & Age/sex & Clinical features & Treatment & Outcome & (Refs.) \\
\hline Falini et al (1980) & $\begin{array}{l}\text { Undifferentiated lung } \\
\text { carcinoma }\end{array}$ & $51 / \mathrm{M}$ & $\begin{array}{l}\text { Anemia and } \\
\text { thrombocytopenia }\end{array}$ & Palliative care & $\begin{array}{l}\text { Death ( } 47 \text { days after } \\
\text { admission) }\end{array}$ & (13) \\
\hline Grier et al (2011) & Uterine carcinosarcoma & $72 / \mathrm{F}$ & Thrombocytopenia & Not available & Not available & (14) \\
\hline $\begin{array}{l}\text { Gonzalez-Molina } \\
\text { et al (2018) }\end{array}$ & $\begin{array}{l}\text { Lung neuroendocrine } \\
\text { carcinoma }\end{array}$ & $61 / \mathrm{F}$ & Pancytopenia & Palliative care & $\begin{array}{l}\text { Death ( } 3 \text { weeks } \\
\text { after diagnosis) }\end{array}$ & $(15)$ \\
\hline Kang et al (2019) & $\begin{array}{l}\text { Urinary bladder small } \\
\text { cell carcinoma }\end{array}$ & 66/M & $\begin{array}{l}\text { Anemia and } \\
\text { thrombocytopenia }\end{array}$ & Palliative care & $\begin{array}{l}\text { Death } \\
\text { (intracerebral } \\
\text { hemorrhage, } 1 \text { day } \\
\text { after diagnosis) }\end{array}$ & (16) \\
\hline
\end{tabular}

M, male; F, female.

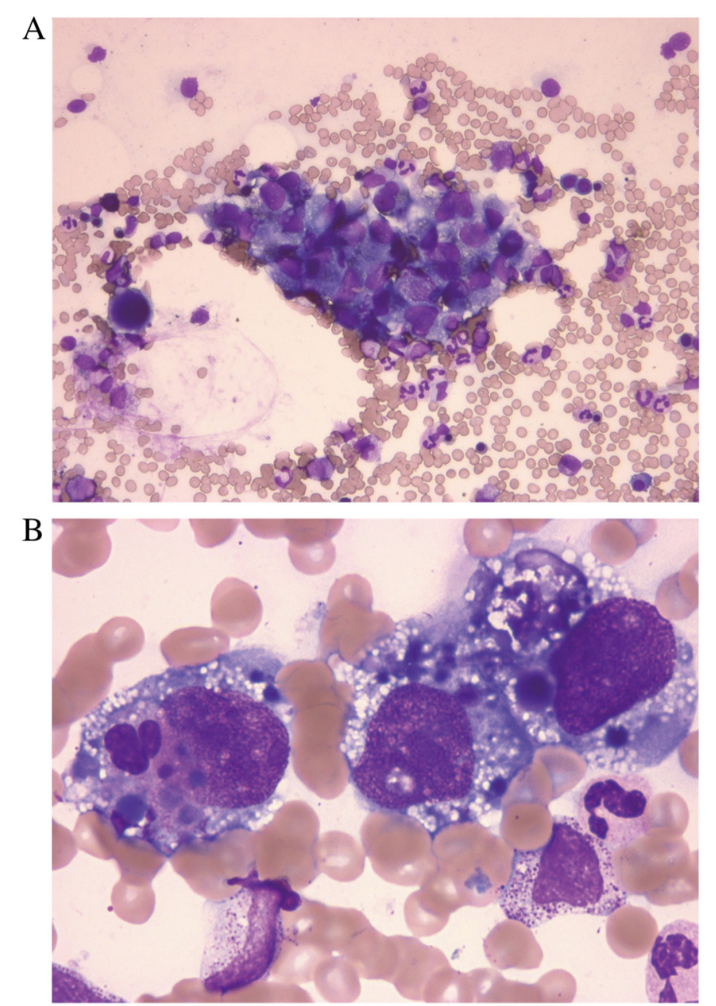

Figure 3. Microscopic analysis after bone marrow aspiration. (A) The aspirated sample contained large atypical cells (bone marrow; Wright-Giemsa stain; magnification, x200). (B) Atypical cells engulfing neutrophils led to nuclei collapse indicating cellular cannibalism (bone marrow; Wright-Giemsa stain; magnification, x1,000).

cannibalism by metastatic cells in the bone marrow have been reported (Table I) (13-16), to the best of our knowledge, this is the first reported case involving a bone marrow metastasis due to MPM.

In conclusion, we have presented a highly unusual case. Further clarification of mechanisms underlying cellular cannibalism by metastatic MPM cells in the bone marrow, with consequent thrombocytopenia, may identify a promising target for treatment of bone marrow metastasis. Moreover, these findings could enable development of more rational and

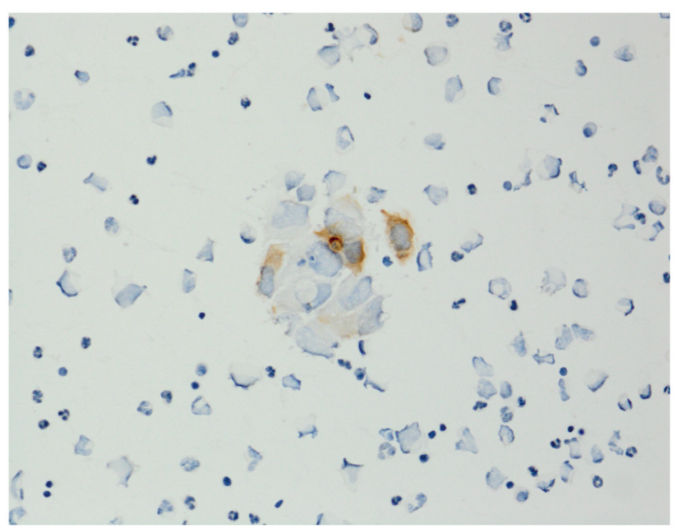

Figure 4. Positive immunohistochemical staining of atypical cells for AE1/AE3 (bone marrow; magnification, x400).

disease-specific strategies for overcoming poor prognosis associated with MPM.

\section{Acknowledgements}

Not applicable.

\section{Funding}

No funding was received.

\section{Availability of data and materials}

The datasets used and/or analyzed during the current study are available from the corresponding author on reasonable request.

\section{Authors' contributions}

$\mathrm{MN}, \mathrm{YK}$ and $\mathrm{KU}$ performed the surgery and perioperative management of the patient. KN and AM contributed to acquisition and analysis of hematological data. YM and HS contributed to acquisition and analysis of pathological data. MN, YK and KU confirm the authenticity of all the raw data. MN, YK, ST, WN and KU drafted the manuscript. ST supervised the 
manuscript writing, editing and review. ST made a significant contribution to interpretation of data. WN and $\mathrm{KU}$ designed and coordinated the project and editing the manuscript. All authors read and approved the final manuscript.

\section{Ethics approval and consent to participate}

Not applicable.

\section{Patient consent for publication}

Written informed consent for the publication of any associated data was obtained from the patient prior to his death.

\section{Competing interests}

The authors declare that they have no competing interests.

\section{References}

1. Robinson BW and Lake RA: Advances in malignant mesothelioma. N Engl J Med 353: 1591-603, 2005.

2. Husain AN, Colby T, Ordonez N, Krausz T, Attanoos R, Beasley MB, Borczuk AC, Butnor K, Cagle PT, Chirieac LR, et al: Guidelines for pathologic diagnosis of malignant mesothelioma: 2012 update of the consensus statement from the International Mesothelioma Interest Group. Arch Pathol Lab Med 137: 647-667, 2013.

3. Boutin C and Rey F: Thoracoscopy in pleural malignant mesothelioma: A prospective study of 188 consecutive patients. Part 1: Diagnosis. Cancer 72: 389-393, 1993.

4. Papac RJ: Bone marrow metastases. A review. Cancer 74 : 2403-2413, 1994.

5. Ihara H, Harada N, Shimada N, Kanamori K, Hayashi T, Uekusa T and Takahashi K: Malignant pleural mesothelioma with bone marrow metastases. Intern Med 57: 2541-2545, 2018.

6. Lugini L, Matarrese P, Tinari A, Lozupone F, Federici C, Iessi E, Gentile M, Luciani F, Parmiani G, Rivoltini L, et al: Cannibalism of live lymphocytes by human metastatic but not primary melanoma cells. Cancer Res 66: 3629-3638, 2006.
7. Finn RS, Brims FJH, Gandhi A, Olsen N, Musk AW, Maskell NA and Lee YCG: Postmortem findings of malignant pleural mesothelioma: A two-center study of 318 patients. Chest 142: $1267-1273,2012$

8. Gupta N, Jadhav K and Shah V: Emperipolesis, entosis and cell cannibalism: Demystifying the cloud. J Oral Maxillofac Pathol 21: 92-98, 2017.

9. Durgan J and Florey O: Cancer cell cannibalism: Multiple triggers emerge for entosis. Biochim Biophys Acta Mol Cell Res 1865: 831-841, 2018.

10. Lozupone F, Perdicchio M, Brambilla D, Borghi M, Meschini S, Barca S, Marino ML, Logozzi M, Federici C, Iessi E, et al: The human homologue of Dictyostelium discoideum phg1 A is expressed by human metastatic melanoma cells. EMBO Rep 10: 1348-1354, 2009.

11. Lozupone F, Borghi M, Marzoli F, Azzarito T, Matarrese P, Iessi E, Venturi G, Meschini S, Canitano A, Bona R, et al: TM9SF4 is a novel V-ATPase-interacting protein that modulates tumor $\mathrm{pH}$ alterations associated with drug resistance and invasiveness of colon cancer cells. Oncogene 34: 5163-5174, 2015

12. Fais S and Overholtzer M: Cell-in-cell phenomena in cancer. Nat Rev Cancer 18: 758-766, 2018.

13. Falini B, Bucciarelli E, Grignani F and Martelli MF: Erythrophagocytosis by undifferentiated lung carcinoma cells. Cancer 46: 1140-1145, 1980.

14. Grier DD, Anz BM and Sirintrapun SJ: Hemophagocytic tumor cells in carcinosarcoma bone marrow metastasis. Am J Hematol 86: 192, 2011.

15. Gonzalez-Molina W, Avila-Polo R, Morales-Camacho RM, Vargas MT, Bernal R and Prats-Martin C: Bone marrow erythrocyte and neutrophil phagocytosis and cannibalism by neuroendocrine carcinoma. Br J Haematol 183: 537, 2018.

16. Kang H, Kim DH, Lee W, Ha J, Ryoo N, Jeon DS and Jung HR: First case of cellular cannibalism in small-cell carcinoma of the bladder detected in peripheral blood. Ann Lab Med 39: 400-402, 2009.

(c) (i) $\ominus$ This work is licensed under a Creative Commons Attribution-NonCommercial-NoDerivatives 4.0 International (CC BY-NC-ND 4.0) License. 